\title{
Los controles a la administración pública en Colombia. Una aproximación al control social al presupuesto participativo en Medellin
}

\section{Controls to the Public Administration in Colombia: An approach from the social control and from the Participative Budgeting in Medellin}

\section{Maria Helena Franco Vargas (D)}

Universidad EAFIT

mafranco@eafit.edu.co

\section{Maria Fernanda Ramirez Brouchoud (D)}

Universidad EAFIT

mframire@eafit.edu.co

\section{Maria Antonia Chinkousky Giraldo (D)}

Universidad EAFIT

mchinkou@eafit.edu.co

\section{Resumen}

El artículo describe los controles a la Administración Pública en Colombia y caracteriza los controles al Presupuesto Participativo (en adelante PP) en Medellín, con especial atención al control social que se ejerce sobre este mecanismo de participación que involucra la decisión sobre recursos públicos. La investigación que soporta este texto, planteó como hipótesis que el modelo de controles al cual ha estado sujeto el PP en Medellín, desde 2012 al 2017, ha presentado fallas en su implementación, lo cual ha incidido en su eficacia. Dentro de las conclusiones se destaca que lo relativo al control social, especificamente, ha presentado problemas relacionados con el conocimiento de la ciudadanía frente al PP, la inexistencia de rendiciones de cuentas focalizadas en el PP y la escasa participación ciudadana, todo cuanto ha conducido a que el control social al PP haya sido bajo dentro del periodo de estudio.

Palabras Clave: Administración pública, presupuesto participativo, controles públicos, control social, Medellín.

\section{Abstract}

This paper exposes the controls to the Public Administration in Colombia and differentiates controls to the Participative Budgeting (from now on PP) in Medellin, making special emphasis on the social control exercised over this mechanism 
of participation which involves decisions taking and management of public resources. The investigation where this paper came from, proposed as hypothesis that the controls system, that rules the PP Budgeting in Medellin from 2012 to 2017, has presented failures regarding its implementation. This has influenced the control to be less effective during the delimited period. Within the conclusions, it is noted that specifically with reference to the social control, it is featuring problems related with the acquaintance of the citizenship towards the PP, the absence of accountability targeting the PP and the lack of citizen participation. All of which has led to having a weak social control of the PP during the study period.

Key Words: public administration, participative budgeting, state controls, social control, Medellín.

Articulo: Recibido el 30 de julio de 2018 y aprobado el 22 de octubre de 2018.

\section{Cómo citar este articulo}

Franco Vargas, MH., Ramírez Brouchoud, MF., Chinkousky Giraldo, MA (2019). Los controles a la administración pública en Colombia. Una aproximación al control social al presupuesto participativo en Medellín, Reflexión Politica 21(41), pp. 50-63. DOI: https://doi.org/10.29375/01240781.3320

\section{Introducción}

Desde los estudios clásicos de la Administración Pública, como puede observarse en los trabajos de Harmon y Mayer (1999), Valadés (2005), Moreno (2014), Oszlak (2014) y Balbín (2015) el control público se concibe como una función estatal y tiene un fundamento democrático, de manera que la sociedad le entrega al Estado una parte de sus recursos para que los administre y los utilice en la obtención de bienes y servicios que satisfagan los intereses comunes. Así, el ejercicio democrático exige que los gobernantes rindan cuentas de sus actos y que, por tanto, se concreten distintas formas de control: el control vertical, el horizontal (dado por los poderes entre sí), el control de los derechos del ciudadano (ejercidos por los defensores del pueblo), el control sobre los presupuestos, el control de los movimientos sociales e incluso el control por parte de la opinión pública (Moreno, 2014, p. 17). Por lo tanto, el control, además de fundamentarse en el Estado de Derecho, es un medio para lograr que la Administración Pública (en adelante AP), en su conjunto, cumpla con sus objetivos. Además, el control es necesario para los procesos de toma de decisiones, por ejemplo, en la definición de las políticas públicas, dado que se debe contar con información oportuna y precisa para su diseño, puesta en marcha y evaluación.

Con base en lo anterior, el objetivo de este texto es presentar algunos de los resultados de la investigación "Los controles al presupuesto participativo en Medellín"1, la cual, por un lado, buscó caracterizar los distintos tipos de controles vigentes en Colombia respecto a los actos de la Administración y el manejo de los recursos públicos. Por otro lado, y de manera específica, pretendió identificar los controles que operan sobre el presupuesto participativo (en adelante PP) en Medellín. Por último, se planteó analizar de manera particular el control social al PP en dicha ciudad en el periodo 2012-2017, a partir de la hipótesis según la cual, este tipo de control ha presentado fallas en su implementación relacionadas con la transparencia, la rendición de cuentas y la participación ciudadana y ello ha incidido en su eficacia.

Cabe señalar que existen trabajos sobre el PP en Colombia, e incluso algunos de ellos abordan la experiencia específica en Medellín, como lo son Betancourt (2005), Gómez (2007), Urán (2007), etc. No se dispone de un estudio que, de manera puntual, se encargue de revisar el tema de los controles que operan

$1 \quad$ Realizada por las autoras en el año 2017 en la Universidad EAFIT, en el marco del semillero de investigación en Gobierno y Políticas Públicas en el cual participan estudiantes de las carreras de Ciencias Políticas y Derecho, integrado en la actualidad por los siguientes estudiantes: María Antonia Chinkousky (coordinadora), María Camila Roldán, Daniela Báez, Julián Ramírez y Jacobo Morales. Vale la pena anotar que dicho proyecto se fundamenta y justifica a partir de investigaciones previas de las autoras, entre ellas, Franco y Ramírez (2013) "Eficacia, eficiencia y gobernanza del proceso de decisión, mediante presupuesto participativo, del gasto en educación superior: El caso de Medellín 2010-2012". Universidad EAFIT. 
sobre el mismo. Así, la inexistencia de trabajos que le den un tratamiento descriptivo y analítico al tema del PP en clave de controles, justifica la investigación de la cual se derivan algunos de los resultados que se presentan en este texto. Por otra parte, si se tiene en cuenta que en los últimos diez años los recursos del PP en Medellín ascendieron a 1,5 billones de pesos ${ }^{2}$, cobra relevancia indagar acerca de cómo opera el control social sobre tal magnitud de recursos públicos.

En ese orden de ideas, el artículo está dividido en cuatro partes: en la primera, se presentan los referentes teóricos; en la segunda, se describe el proceso metodológico llevado a cabo; en la tercera, se evidencian algunos de los hallazgos de la investigación con particular énfasis en el control social al PP en Medellín; y finalmente, se plantean unas conclusiones.

\section{Referentes teóricos}

\subsection{Los controles a la Administración pública en el contexto contemporáneo}

El contexto actual en el que las administraciones públicas llevan a cabo su actividad -marcado por la descentralización y desconcentración administrativas, la externalización de servicios, las asociaciones público-privadas, entre otros elementos- demanda una adaptación de los mecanismos de control tradicionales (verticales, jerárquicos, "weberianos"), a fin de tramitar y satisfacer las nuevas y crecientes demandas ciudadanas, así como dar cuenta de las propias transformaciones en los roles y funciones de los Estados Nacionales.

Es precisamente bajo el sistema republicano de gobierno y con la división de poderes en ramas y órganos del poder público, que se desarrolla el sistema de controles públicos; junto con este, los llamados órganos de control y los distintos instrumentos previstos para ejercer el control público están consagrados constitucional y legalmente. De acuerdo con Moreno (2014), en términos generales, este control público tiene un triple carácter: en primer lugar, es político y está reservado a los órganos que encarnan el ideal democrático, es decir, los congresos o legislaturas, y está encaminado a evaluar si la acción de la AP está de acuerdo con los fines del Estado. En segundo lugar, es de carácter técnico, en cabeza de los órganos de control, quienes deben ser independientes y se ocupan de verificar la legalidad, los aspectos financieros, contables, patrimoniales, operativos, los resultados, entre otros. Por último, además de estos controles institucionales, en el marco de una verdadera democracia debe operar el control social (2014, p. 25).

Hablar de control público hoy en día implica, de manera ineludible, asociarlo al Estado abierto y a la gobernanza, cuestiones que en los últimos años se fundamentan desde la academia -trabajos como los de Oszlak, (2014) y Pollit y Bouckaert, (2004)- y se propagan desde distintos espacios gubernamentales y organizaciones internacionales. En el ámbito latinoamericano, vale la pena anotar que en 2016 a instancias del CLAD se aprobó la Carta Iberoamericana de Gobierno Abierto (en adelante CIGA) en el marco de la XVII Conferencia Iberoamericana de Ministras y Ministros de Administración Pública y Reforma del Estado, que tuvo lugar en Bogotá, Colombia. La CIGA retomó y articuló una serie de principios contenidos en Cartas precedentes a fin de proporcionar una ruta para la apertura gubernamental en Iberoamérica (CLAD, 2016). Cabe decir que la mayoría de los gobiernos en América Latina, en los últimos años, incorporaron en sus planes de acción diversas iniciativas y proyectos con el objetivo de aumentar la capacidad institucional, de cara a una gestión abierta y con mecanismos de control acordes y efectivos. En otras palabras, el control público en la actualidad es indisociable de los principios de transparencia, rendición de cuentas y gestión participativa, todos ellos elementos constitutivos de la nueva gobernanza.

Colombia no ha sido ajena a este proceso. Prueba de ello es que, desde la Constitución de 1991 en adelante, ha experimentado diversos cambios institucionales a fin de adaptarse a las tendencias globales previamente señaladas. Como plantea Isaza (2015, p. 340), se fortalecieron los pesos y contrapesos, la estructura y el funcionamiento de los órganos de control independientes, el accountability social y distintos mecanismos de participación democrática.

En el mismo sentido, Restrepo (2011) plantea que atendiendo al modelo de nueva gestión pública en auge en los años ochenta y noventa 
del siglo XX, la Constitución de 1991 adopta un criterio de especialización funcional, por fuera de la jerarquización de las ramas del poder público, sobre todo la ejecutiva, "consagrando la existencia autónoma e independiente de los organismos de control, de las autoridades electorales y de ciertos órganos y entidades que antes hacían parte de la rama ejecutiva o que se crean a partir del nuevo régimen constitucional” (2011, p. 311)

\subsection{Participación ciudadana y control social}

Para abordar la cuestión del control social al PP en Medellín en los últimos cinco años, se partió de la categoría participación ciudadana. Esta categoría se aborda en dos sentidos: como acción política y como derecho. Lo primero supone analizarla desde el punto de vista politológico y sociológico, lo cual implica reconocerla como el conjunto de acciones dirigidas a influir en el proceso político democrático, mediante el voto, la militancia en un partido político, la deliberación e incluso la protesta social, y demás modalidades no institucionalizadas de participación. Igualmente, vale la pena mencionar que, en las distintas definiciones de participación entendida como acción política, se hace referencia a la participación de los ciudadanos en acciones voluntarias relativas al gobierno y a la política en sentido amplio y que no está restringida a la contienda electoral (Sancari, 2016, p. 20). En la actualidad, y en función del diseño y formulación de políticas públicas, el Estado debe alentar la participación y así buscar no solo un aumento en la legitimidad, sino de la eficacia de los gobiernos que se benefician con las capacidades de la ciudadanía. Esta participación como acción, debe ir de la mano de derechos como la libre expresión, la libre asociación y la libertad de prensa y de opinión.

Por otro lado, siguiendo al mismo autor (con un enfoque más jurídico), la participación entendida como derecho- implica pensarla como un derecho fundamental asociado a la dignidad humana, a la autonomía y a la libertad e igualdad de las personas. Cobra importancia resaltar en este punto los aportes de autores como Rawls y Waldron, citados por Sancari (2016, p. 30), en el sentido que defienden el ideal de una participación constante y equitativa en los asuntos públicos, al combinar un modelo de participación y deliberación.

Con base en esto último, y teniendo en cuenta las transformaciones que datan de la década del 2000 en América Latina, se crean una serie de mecanismos de participación ciudadana que buscan ahondar en la cogestión, la corresponsabilidad, la eficacia de las políticas y, de esa manera, pasar de la gobernabilidad a la gobernanza como modelo de administración de lo público, que involucra a la ciudadanía en la toma de decisiones. Todo ello, con la idea de transitar de una democracia formal, legal y representativa a un modelo sustantivo, material, social y participativo, en donde los "mecanismos de participación, con la creación de espacios de cogestión en niveles comunales, contribuirán a convertir al 'ciudadano votante' en ciudadano directamente interviniente en el contenido y diseño de las políticas públicas” (Sancari, 2016, p. 37).

Dentro del ordenamiento jurídico colombiano, a nivel constitucional, se encuentra que la participación ciudadana se refiere al derecho que tiene todo ciudadano a participar en la conformación, ejercicio y control del poder político (Const., 1991, art. 40). Igualmente, el artículo 270 superior se refiere a las formas y sistemas participativos para vigilar la gestión pública en los diferentes niveles administrativos y sus resultados (Const., 1991, art. 270). Desde el punto de vista legal, se destacan las leyes 134 de 1994 y 1757 de 2015 sobre promoción y protección del derecho a la participación democrática, y la Ley 850 de 2003 sobre veedurías ciudadanas.

\subsection{El presupuesto participativo en Medellin}

Los antecedentes del PP a nivel internacional, específicamente en Iberoamérica, se remontan a los años 80 del siglo pasado. Su origen se encuentra en la ciudad de Porto Alegre, Brasil, donde el PP se concibe fundamentalmente como una forma de democracia participativa, un mecanismo de cogestión, un instrumento para la descentralización del gasto y un importante vehículo de inclusión social (Urán, 2007). Los inicios de la década del 2000 corresponden a la masificación del proceso en Brasil, con la expansión a numerosos municipios, y luego su "exportación" a otros países. Además del caso brasileño, se destacan algunas prácticas del PP en Argentina y España. Actualmente, se constata que muchos países latinoamericanos han 
adoptado iniciativas similares a nivel local, entre ellos: México, Bolivia, Uruguay, Colombia, Ecuador, Guatemala, Nicaragua, República Dominicana, El Salvador, Perú y Chile. Es de notar que el grado de institucionalidad del PP en América Latina es disímil, en cuanto a la formalización del proceso y la legislación que lo ampara - en algunos casos inexistente- (Montecinos, 2012).

Más allá de la diversidad de experiencias, existe cierta coincidencia en la literatura consultada en cuanto a la definición del PP como:

(...) una herramienta de política pública que garantiza la participación ciudadana en la toma de decisiones públicas relativas a los gastos de inversión. Dicha participación implica no solo que la comunidad exprese directamente (a través de asambleas, debates y consultas) cuáles son sus necesidades en materia de bienes públicos, sino que las priorice, participe en la formulación de proyectos y proponga la distribución de recursos de inversión. (Franco, 2010, p. 54)

Es decir, el PP procura establecer una práctica de cogestión que rompe con las barreras burocráticas existentes entre la AP y la ciudadanía.

$\mathrm{Si}$ se tiene en cuenta que el PP es un mecanismo que permite entregarle un porcentaje de los recursos de inversión a la comunidad, para que ella directamente decida en qué gastarlos, la pregunta por el control de estos se vuelve necesaria. En este orden de ideas, si el PP implica el manejo de recursos públicos a partir de un ejercicio de democracia participativa, los controles al mismo no sólo deben ser de tipo ciudadano, sino también de tipo fiscal, presupuestario y político.

Para el caso de Medellín, el Acuerdo Municipal 43 de 2007 creó e institucionalizó la planeación local y el PP en el marco del Sistema Municipal de Planeación. El artículo 63 de este acuerdo definió el PP como una "herramienta de gestión participativa de los recursos de inversión asignados a las comunas y corregimientos que hacen parte del presupuesto anual del municipio" (2007, art. 63). Aunado a lo anterior, se debe destacar que en 2017 el Concejo de Medellín, por iniciativa de la Administración, como de la Secretaría de Participación Ciudadana, promulgó el Acuerdo Municipal 28 de 2017, mediante el cual se profundiza en temas como las evaluaciones de impacto al PP, su incidencia en el Índice de Desarrollo Humano, la construcción de indicadores, así como en la necesidad de hacer ajustes a los distintos tipos de control al mismo.

De esta manera, en el marco de la institucionalidad antes mencionada, el PP en Medellín ha sido una herramienta de gestión participativa de los recursos de inversión asignados a las comunas y corregimientos, los cuales hacen parte del presupuesto anual del municipio. Ello se concreta en el hecho de que el Departamento Administrativo de Planeación asigna un componente llamado PP que no puede ser inferior al 5\% de dicho plan. Estos recursos se reparten de forma diferencial y equitativa, según las particularidades del territorio y las condiciones socioeconómicas de la población.

\section{Proceso metodológico}

Respecto a la metodología del proyecto, esta fue descriptiva y exploratoria mediante una estrategia de investigación cualitativa. Esto se llevó a cabo por medio de las siguientes técnicas de investigación: revisión documental y normativa respecto a los controles a la AP en Colombia y, especialmente, para el PP en Medellín. Adicionalmente, se ocupó de describir las cualidades del control social al PP en la ciudad de Medellín desde 2012 a 2017, a partir del análisis de las encuestas de percepción ciudadana, la revisión de la agenda noticiosa y la realización de entrevistas a actores clave. Para la sistematización de la información se emplearon herramientas como las bases de datos especializadas de la Biblioteca de la Universidad EAFIT (Descubridor) y el software de análisis cualitativo ENVIVO.

Partiendo de lo anterior, este trabajo se ejecutó en dos etapas: primero, se realizó la revisión de la literatura especializada desde el derecho público y la ciencia política. Se analizaron en particular los textos de Restrepo (2015), Santofimio (1998), Rodríguez (2015), Moreno (2014), Oszlak (2014) y Sancari (2016), entre otros. Luego se llevó a cabo la revisión normativa, particularmente normas de la Constitución de Colombia, como la Ley 1757 (2015), la Ley 1755 (2015), la Ley 1712 (2014), los Acuerdos Municipales 43 de 2007 y 28 de 2017, entre otros. Por otra parte, se revisaron las encuestas de percepción ciudadana del Observatorio de Medellín Cómo Vamos, entre 2009 y 2017, así como la agenda noticiosa sobre el control social al PP en Medellín entre 2012 y 2017. Posteriormente, se procedió a la sistematización de la información por medio de mapas conceptuales, sistemas categoriales, análisis 
de prensa, cuadros normativos, estructuración de la matriz de análisis y fichas bibliográficas.

En segundo lugar, se efectuó el trabajo de campo a través de la realización de siete entrevistas $^{3}$ semiestructuradas a actores clave respecto al control social sobre el PP en Medellín, distribuidos así: tres concejales del municipio de Medellín, dos funcionarias del gobierno municipal, especificamente de la Secretaría de Participación, y dos directoras de Veedurías u Observatorios ciudadanos; todos accedieron a ser entrevistados con previo consentimiento informado ${ }^{4}$. En todo este proceso se tuvieron en cuenta tanto los diarios de campo de los investigadores como la observación en campo sistematizada a partir de memos. La metodología también involucró la construcción de la siguiente matriz analítica (Tabla 1) que sirvió de estructura para las entrevistas, para volcar la información y clasificarla:

A continuación, se presentan algunos de los hallazgos obtenidos en cuanto a la revisión documental y normativa respecto a los controles a la AP en Colombia y, en especial, al PP en Medellín. Igualmente se evidencian los resultados con relación al control social al PP, a partir del análisis de las encuestas de percepción ciudadana, la revisión de la agenda noticiosa y las entrevistas a los actores clave.

\section{Algunos hallazgos}

\subsection{Los controles a la AP en Colombia}

Tabla 1.

Matriz Analitica
A partir de la revisión normativa y doctrinaria se encuentra que, dentro de la estructura del poder público en Colombia, están previstos una serie de controles sobre las actividades de la AP: control administrativo, fiscal, político, disciplinario y social. Estos controles están establecidos en la Constitución, las leyes y las sentencias de las Altas Cortes, los cuales se describen a continuación:

\section{a. El control administrativo}

Es un tipo de autocontrol de la administración y se realiza a través de las oficinas de control interno. Fue creado para complementar el control externo de la gestión financiera del Estado. Así, el inciso 2 del artículo 209 de la Constitución política establece: "La administración pública, en todos sus órdenes tendrá un control interno que se ejercerá en los términos que señale la ley" (Const., 1991, art. 209). En ese sentido, todas las entidades públicas de cada uno de los entes territoriales están obligadas a diseñar procedimientos de control interno el cual es el conjunto de métodos que una entidad adopta, con el fin de que todas las actividades dentro de ella se realicen de acuerdo con las normas constitucionales y legales vigentes (Ley 87 de 1993).

Adicionalmente, dentro del control administrativo, también se encuentra el financiero o también llamado control económico, el cual es ejercido por la Dirección General de Presupuesto y por el Departamento Nacional de Planeación (DNP), quienes se encargan de calificar los resultados

\begin{tabular}{llll}
\hline \multicolumn{1}{c}{$\begin{array}{c}\text { Tipo } \\
\text { de control }\end{array}$} & Actores & \\
\cline { 2 - 3 } & Concejales & $\begin{array}{l}\text { Personeria / Medellin } \\
\text { Cómo Vamos }\end{array}$ & $\begin{array}{l}\text { Secretaria de } \\
\text { Participación Ciudadana }\end{array}$ \\
\hline Control politico & & \\
\hline Control social & & \\
\hline Control fiscal & & \\
\hline
\end{tabular}

Fuente: elaboración propia. Semillero de investigación, Gobierno y Políticas Públicas, Universidad EAFIT.

3 Los resultados de las entrevistas no son estadísticamente significativos toda vez que se privilegió una representatividad sustantiva, pues se buscaba cubrir las situaciones sociales de mayor relevancia para la investigación (Corbetta, 2003).

$4 \quad$ Los extractos de las entrevistas se transcribieron literalmente. 
alcanzados y medir la eficacia y la productividad de la gestión presupuestal. Cabe resaltar que el DNP tiene la responsabilidad del diseño y la organización de los Sistemas de Evaluación de Gestión y Resultados de la Administración Pública, mediante un indicador sintético que incluye un componente fiscal desde el año $2000^{5}$, en lo relacionado con políticas y proyectos de inversión. Este control es ejercido por la misma AP, pues ambos órganos pertenecen al Poder Ejecutivo.

\section{b. El control disciplinario}

Es realizado por el Ministerio Público, en cabeza del Procurador General de la Nación, el Defensor del Pueblo y los Personeros Municipales. Así, a los agentes del Ministerio Público les corresponde la guardia y promoción de los derechos humanos, la protección del interés público y la vigilancia del cumplimiento de la Constitución, las leyes, las decisiones judiciales y los actos administrativos (Santofimio, 1998, p. 386).Es decir, el Ministerio Público interviene en diversas esferas públicas en procura del cumplimiento de la ley y la recta administración de justicia. La concepción del Ministerio Público en el derecho colombiano es “(...) una función en cabeza de varias autoridades, aunque bajo la dirección suprema del Procurador General de la Nación en los términos del artículo 275 C.P.” (1998, p. 385).

\section{c. El control fiscal}

Este control está a cargo de la Contraloría General de la República y de las contralorías departamentales y municipales (en los municipios donde las hubiera). Mediante el control fiscal se vigila la gestión de los ingresos y gastos de la Administración y de los particulares o entidades que manejan fondos o bienes de la nación. Este control se fundamenta en valores como la eficiencia, la eficacia, la economía, la equidad y la valoración de los costos ambientales. En el ejercicio del control fiscal se implementan ciertos mecanismos como el control de legalidad, control de gestión, control de resultados y revisión de cuentas. Cabe aclarar que la Constitución de 1991 eliminó el control fiscal previo y lo sustituyó por el control fiscal posterior y selectivo, el cual es ejercido por la Contraloría General de la República. Igualmente, existen leyes ordinarias que regulan el control fiscal: Ley 42 de 1993, sobre la organización del sistema de control fiscal financiero y los organismos que lo ejercen; Ley 330 de 1996, por la cual se desarrolla parcialmente el artículo 308 de la Constitución Política de Colombia (1991) y se dictan otras disposiciones relativas a las Contralorías Departamentales; como la Ley 617 del 2000, por la cual se dictan otras normas tendientes a fortalecer la descentralización y la racionalización del gasto público nacional. Por otra parte, el estatuto anticorrupción está regulado por la Ley 1474 del 2011.

\section{d. El control político}

A nivel nacional lo realiza el Congreso de la República, el cual se vale de cuatro mecanismos, según Restrepo (2015):

1) Citación a los ministros a las sesiones plenarias o a las comisiones constitucionales.

2) Citación a los jefes de departamento administrativo a las comisiones constitucionales.

3) Realización de un examen sobre el informe de la ejecución de los planes y programas que hace referencia el Art 325 de la Constitución.

4) Aprobación de la cuenta general del presupuesto y del tesoro. Así mismo, se destaca que en los entes territoriales el control político lo ejercen las Asambleas Departamentales y los Concejos Municipales, como órganos colegiados encargados de hacer este tipo de controles a los actos y dineros de la administración local. (p. 475)

\section{e. El control social}

Este tipo de control sobre los actos y recursos de la AP es un derecho y un deber de la ciudadanía para vigilar y fiscalizar la gestión pública y la prestación de servicios ofrecidos por el Estado o por particulares que cumplan función pública. El control social es una modalidad de participación ciudadana y uno de sus principales ejes, que está consagrado en el art. 270 de la Constitución (Const., 1991, art. 270). De esta manera los ciudadanos, individualmente considerados o de manera colectiva, le hacen seguimiento y control a las políticas públicas, intervienen en su

$5 \quad$ Ver en la página web del DNP este indicador: https://www.dnp.gov.co/programas/desarrollo-territorial/evaluacion-yseguimiento-de-la-descentralizacion/Paginas/documentos-de-evaluacion.aspx 
formulación y diseño, velan por el uso correcto de los recursos públicos, supervisan la ejecución de los contratos estatales y previenen riesgos en la gestión pública. En otras palabras, mediante el ejercicio constante y activo del control social, el ciudadano puede influir, orientar, corregir y evaluar las políticas públicas con el fin de lograr los propósitos de estas.

Según la Ley 1757 de 2015, a través del control social se busca fortalecer la cultura de lo público, prevenir hechos de corrupción, fortalecer la participación ciudadana y apoyar la labor de los órganos de control independientes. El control social se concreta mediante el uso de diferentes mecanismos de participación ciudadana, como el derecho de petición, las acciones constitucionales de tutela, populares, de grupo, de cumplimiento, o mediante reclamos, quejas, denuncias, etc.

De igual manera, algunas leyes relacionadas con el control social buscan desarrollar derechos fundamentales como el derecho al acceso a la información pública, el derecho de petición y la participación democrática, entre otros. Ejemplos de estas leyes son las estatutarias: Ley 850 del 2003, por medio de la cual se reglamentan las Veedurías Ciudadanas; Ley 1755 del 2015, por medio de la cual se regula el derecho fundamental de petición; Ley 1712 del 2014, por medio de la cual se crea la Ley de Transparencia y del Derecho de Acceso a la Información Pública Nacional y se dictan otras disposiciones; Ley 1757 del 2015, por la cual se establecen disposiciones en materia de promoción y protección del derecho a la participación democrática; y la Ley 136 de 1994, por la cual se dictan normas tendientes a modernizar la organización y el funcionamiento de los municipios.

Finalmente, una forma de concretar el control social es a partir de las Veedurías Ciudadanas ${ }^{6}$, las cuales actúan mediante la acción colectiva promovida por movimientos sociales. Estas pueden estar acompañadas por el Ministerio Público, en especial mediante las Defensorías del Pueblo y las Personerías Municipales, quienes velan por la protección de los derechos de los ciudadanos (en este caso, por el derecho a la participación ciudadana). Frente al control social ejercido directamente por la ciudadanía, hay que considerar, siguiendo a Marín (2008), que hoy el control de lo público trasciende lo exclusivamente estatal y la institucionalidad, pues las relaciones entre Estado y sociedad se han transformado y exigen de esta última nuevos roles asociados a la coordinación, cogestión, vigilancia y control sobre lo público (2008, p. 196).

De todo lo anterior, se puede observar que en Colombia existen formalmente diversos controles a los actos de la AP y específicamente sobre el manejo de los recursos públicos. Estos controles son coherentes con las nuevas tendencias de la AP, relativas al Estado abierto, la transparencia de los actos gubernamentales y la rendición de cuentas, entre otras.

\subsection{Los controles al PP en Medellín}

Estos controles mencionados previamente operan también para el PP en Medellín, de acuerdo con lo estipulado en la Constitución Política y las leyes. De esta manera, el control político es ejercido por el Concejo de Medellín que, por medio de citaciones a ediles y líderes sociales de las comunas de la ciudad, realiza rendiciones de cuentas y seguimiento a los dineros del PP invertidos en diferentes proyectos. Esto puede evidenciarse en las actas del Concejo donde se recoge toda la información de dichas reuniones. Así mismo, el control fiscal lo realiza la Contraloría de Medellín, es posterior y selectivo. Se destacan los derechos de petición por parte de la ciudadanía, cuando se presume una irregularidad en algunos de los proyectos ejecutados con dineros del PP. Estos reportes se pueden solicitar a la Contraloría de Medellín y se encuentran en los registros de esta. Por otro lado, el control social es ejercido por la ciudadanía a través de Veedurías Ciudadanas y Observatorios, para esto cuentan con el apoyo de la Secretaría de Participación Ciudadana y más específicamente del Observatorio de Planeación Local y PP. La participación ciudadana se puede observar en las diferentes denuncias, quejas y reclamos que se hacen ante el Concejo y la Contraloría de Medellín, como en la asistencia a eventos del PP y los encuentros realizados por la Secretaría de Participación.

En resumen, en Medellín existe un gran desarrollo normativo acerca de los diversos controles al PP (social, político y fiscal), los cuales

$6 \quad$ Consagradas constitucionalmente a partir del artículo 91 y reglamentadas por las leyes 850/03 y la Ley Estatutaria de Participación Ciudadana 1757/15. 


\section{Controles al PP en Medellín}

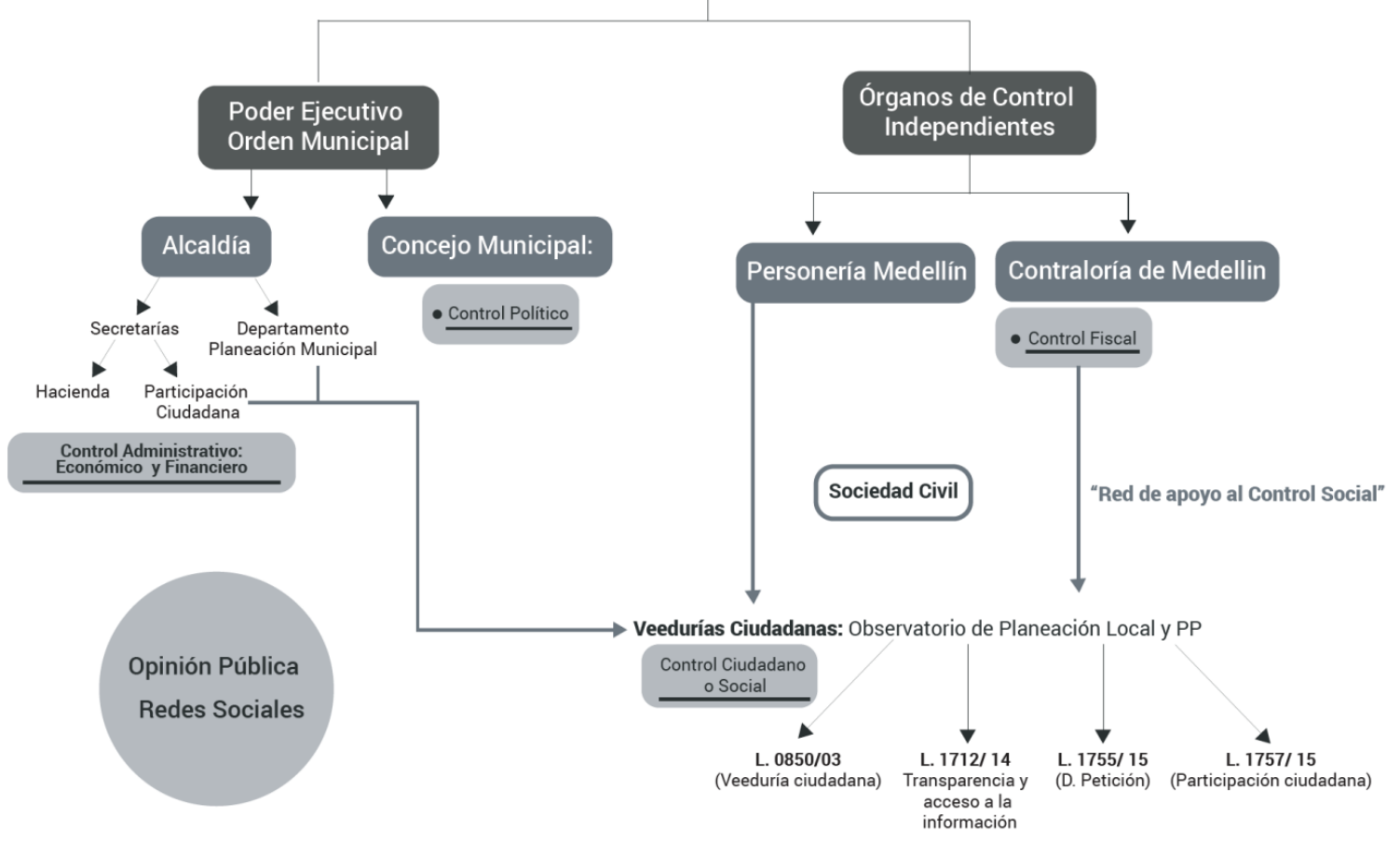

Figura 1. Controles al presupuesto participativo.

Fuente: elaboración propia. Semillero de investigación, Gobierno y Políticas Públicas, Universidad EAFIT.

se concretan en el plano de lo formal, tal como se puede observar en la Figura 1:

\subsection{El control social al PP en Medellin}

Partiendo de reconocer que el PP en Medellín ha sido concebido como un mecanismo que permite entregarle un porcentaje de los recursos de inversión a la comunidad para que ella decida de forma directa en qué gastarlos, cobra importancia el tema del control social como una garantía constitucional y como un mecanismo de participación y veeduría ciudadana, tal como se verá a continuación:

Según el Acuerdo Municipal 28 de 2017, por medio del cual se modifica el Acuerdo 43 de 2007 y se actualiza el Sistema Municipal de Planeación del Municipio de Medellín, el PP se concibe como un mecanismo de asignación equitativa, racional, eficiente, eficaz y transparente de los recursos públicos, el cual queda inmerso dentro Sistema Municipal de Planeación y cuenta con tres subsistemas: el de Articulación de la Planeación, un subsistema de Organización y Formación para la Participación Ciudadana en la Planeación, y un Subsistema de Seguimiento, Evaluación y Control del Proceso de Planeación. Este último, tiene como objetivo diseñar e incorporar acciones relacionadas con la evaluación y el control de las gestiones y los resultados obtenidos. De manera particular, dicho control social concierne a las veedurías ciudadanas, las juntas de vigilancia, las auditorías ciudadanas y demás instancias de participación ciudadanas; el seguimiento y evaluación le compete al Departamento Administrativo de Planeación y el autocontrol es realizado por la Secretaría de Evaluación y Control o quien haga sus veces.

Entre los hallazgos a destacar de la investigación, llama la atención el conocimiento general que tiene la ciudadanía sobre el PP. Según el análisis de las encuestas de percepción ciudadana del Observatorio de Medellín Cómo Vamos ${ }^{7}$ (20092017) se evidencia que dicho conocimiento, ha

7 https://www.medellincomovamos.org/quienes-somos/ 
aumentado de un $19 \%$ a un $65 \%$ de los encuestados (Figura 2):

Hay que tener en cuenta, en este punto, que la encuesta no indaga acerca de la existencia de controles al PP, por consiguiente, no arroja un dato directo con relación a si la ciudadanía lo controla o no. De allí se puede inferir que no es posible controlar aquello que no se conoce. En ese sentido, la directora del Observatorio afirma:

Si bien existen los controles al PP, dentro de los que están los mecanismos de control social o ciudadano, se presentan debilidades. Así, por ejemplo, por parte de Medellín Cómo Vamos, en la encuesta de percepción, sólo se indaga acerca del conocimiento del PP y de los diferentes programas, pero no de los controles al mismo (P. Restrepo, comunicación personal, 18 de septiembre de 2017).

Esta misma idea se corrobora en la entrevista a uno de los concejales de Medellín, cuando expresa:

Hay poco control social, en parte porque poca gente conoce en general del PP y en consecuencia muy pocos ciudadanos hacen control social. El PP hoy tiene 140.000 mil personas que conocen de él, es el colmo que en una ciudad que tiene $2 \longleftarrow 400.000$ mil habitantes solamente $140.000 \mathrm{mi}$ personas conozcan del PP [...] y no solamente que conozcan su función, su participación y cómo debe hacerse el PP, estamos buscando que las próximas reuniones y asambleas del PP si quiera logremos que $1^{\prime} 000.000$ de personas tengan conocimiento del PP, lo que significa el PP y que lo conozca no solo el viejo o el presidente de la Acción Comunal o de las JAL, que lo conozca también el líder del barrio (R. L. Yepes, comunicación personal, 31 de octubre de 2017).

Igualmente, es significativo el hecho de que los otros dos concejales entrevistados no se hayan pronunciado con relación al control social al PP, a pesar de que la pregunta se les hizo de manera directa. Por otra parte, la escasa presencia del tema en la agenda noticiosa de la ciudad también refuerza la idea de la falta de conocimiento acerca del PP y del control ciudadano al que está sujeto. Es decir, de la búsqueda en las noticias locales sobre el PP en Medellín, más exactamente en el tema del control social al PP, se puede inferir que ha sido tocado de manera muy tangencial. Sólo se hallaron 28 noticias sobre PP y ninguna de ellas da cuenta de controles al PP y mucho menos del control social.

Pese a lo anterior, aunque el conocimiento del PP y de sus controles, en especial el social, son poco sistemáticos, en los últimos cinco años se ha avanzado al respecto, pues el hecho de que hoy

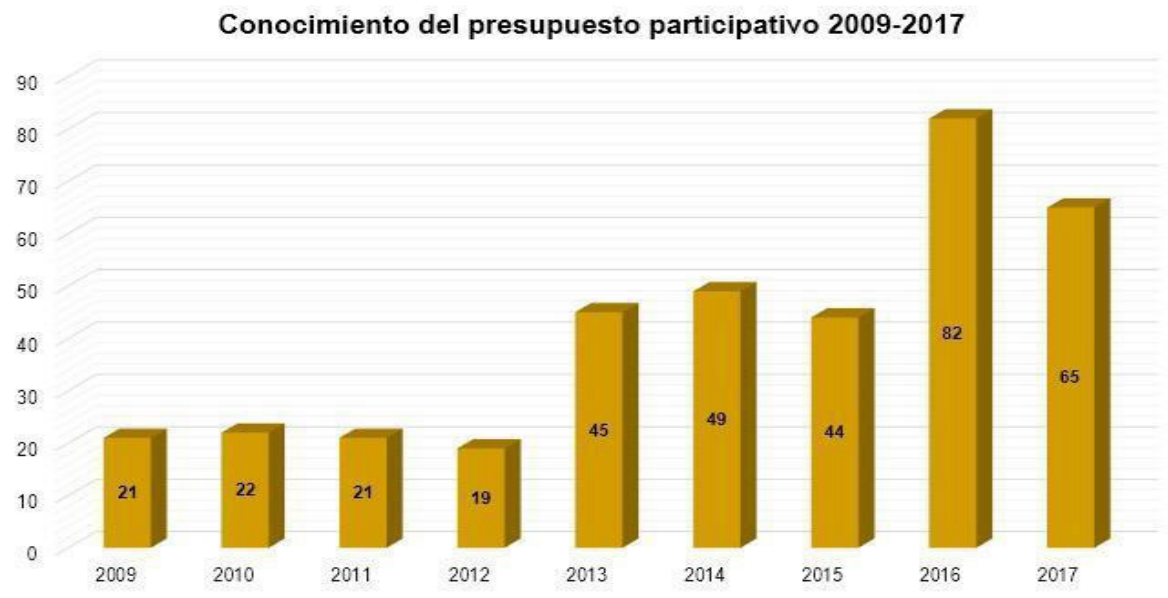

Figura 2. Conocimiento del presupuesto participativo 2009-2017

Fuente: elaboración propia con base en las encuestas de percepción ciudadana del Observatorio de Medellín Cómo Vamos $^{1}$.

$1 \quad$ En la ficha técnica de la encuesta de percepción ciudadana de Medellín Cómo Vamos, se manifiesta que el grupo objetivo es la población general, hombres y mujeres mayores de 18, de estratos sociales 1 al 6 , residentes habituales del área urbana de Medellín en todas sus comunas. La muestra seleccionada sobrepasa las 1.500 encuestas. 
exista un cambio normativo como el del Acuerdo 28 de 2017, que posibilita que instituciones como la Secretaria de Participación, las Veedurías y el Observatorio de Medellín Cómo Vamos, estén discutiendo sobre el PP y los controles a los que debe estar sujeto, hace que de alguna manera este tema se incluya en la agenda pública.

Adicionalmente, $\mathrm{y}$ frente al tema en particular de la rendición de cuentas necesaria para el control social, la directora de Medellín Cómo Vamos expresa la necesidad de focalizar la misma al PP, en tanto hasta el momento solo se aborda de manera general. Es decir, de acuerdo con la entrevistada, es claro que si Medellín Cómo Vamos le pide a la Administración Municipal que le muestre en qué se ha ejecutado el PP en un año determinado, lo más seguro es que se le provea esta información. El problema radica en que esto debería encontrarse vía información pública y no es así (P. Restrepo, comunicación personal, 18 de septiembre de 2017). Llama la atención que si bien la misma Administración afirma que se hace rendición de cuentas cada año y que existe "el día blanco" de la transparencia (que se lleva a cabo para determinar cuál ha sido la inversión del PP), sin embargo, desde Medellín Cómo Vamos, se afirme que dentro de las principales falencias a los controles al PP está la inexistencia de un seguimiento sistemático al mismo. En palabras de su directora, no obstante, se realiza una rendición de cuentas anual:

Esta es muy general ya que no se le hace "zoom" al PP, es decir, no hay un espacio en el que se informe a la ciudadanía sobre la ejecución de este, las obras en que se ha destinado y el proceso de los proyectos en los que se ha invertido y los controles al mismo, en particular el ciudadano o social (P. Restrepo, comunicación personal, 18 de septiembre de 2017).

En cuanto al control social de la Personería de Medellín, se destaca, de acuerdo con la Directora del Observatorio de Planeación que:

La Personería de Medellín elabora un informe al final de cada año sobre Derechos Humanos y ahí nosotros como Observatorio hacemos nuestro aporte dando cuenta de las diferentes actividades que se hicieron durante el año transcurrido, como por ejemplo: acompañamiento a las comunidades, actividades de inspección, vigilancia y control y dentro de esas actividades de vigilancia decimos cuál fue el derecho al que se le hizo inspección (por ejemplo, participación) y cómo se presentó este derecho en las comunidades (A. Maya, comunicación personal, 31 de octubre de 2017).

En ese mismo sentido, la entrevistada aclaró que la Personería de Medellín hace un control a casos específicos del PP, es decir, a proyectos puntuales que se hayan denunciado por irregularidades que se puedan estar presentando en el tema de la participación ciudadana. Así:

Cuando empezamos con el estudio del proyecto hacemos una visita al lugar donde se está desarrollando y posteriormente generamos un informe sobre lo que encontramos alli y si se encontró alguna alerta que puede ser: no hubo participación de la comunidad o la información del presupuesto invertido no corresponde con lo que se está llevando a cabo; remitimos el caso a Vigilancia Administrativa, área de disciplinares, Planeación Local o Participación Ciudadana, según el caso. Nuestro control al PP es más enfocado a la participación de la comunidad en la priorización del presupuesto, lo que hacemos es conseguir pruebas sobre algún tipo de irregularidad $\mathrm{y}$ luego la enviamos al área encargada (A. Maya, comunicación personal, 31 de octubre de 2017).

De lo anterior se colige que el Observatorio de Planeación de la Personería hace un llamado de atención a la misma Administración Local para alertar de una eventual irregularidad y denuncia ante otros entes de control, como la Contraloría Municipal, frente a problemas fiscales y al Concejo de Medellín para el caso del control político. Es decir, se evidencia la manera como el control social ejercido por el Observatorio de la Personería de Medellín incide en el despliegue de otro tipo de controles interno y externos.

Finalmente, según las funcionarias de la Secretaría de Participación entrevistadas, la misma Administración se ocupa del autocontrol al PP, pero se evidencia apatía de la ciudadanía en cuanto a la participación en los procesos de este y su control, lo cual se profundiza debido a la existencia de canales clientelares al interior del PP que desestimulan dicha participación. Esto concuerda con las cifras de la Secretaría de Participación, obtenidas mediante derecho de petición, que muestran la baja participación de la ciudadanía en el período de estudio (ver Figura 3). Por lo anterior, en palabras de las 
entrevistadas, "la actual Administración ha querido resignificar e impulsar la participación ciudadana" (Tamayo y Echeverri, comunicación personal, $19 \mathrm{de}$ octubre de 2017). Esto quedó contemplado no sólo en el Plan de Desarrollo Municipal vigente, sino en el Acuerdo 28 de 2017 y en los ajustes institucionales para mejorar y apoyar este proceso.

\section{Conclusiones y recomendaciones}

Con la revisión normativa y doctrinaria realizada, se concluye que en Colombia existen formalmente diversos controles a los actos de la AP y específicamente sobre los actos de los funcionarios públicos y el manejo de los recursos públicos. La concepción de estos controles, como se pudo ver, es coherente con las nuevas tendencias de la AP relativas al Estado abierto, la transparencia de los actos gubernamentales, la rendición de cuentas y la gobernanza.

Teniendo en cuenta los hallazgos de la investigación, es posible afirmar que, pese al innegable avance en términos de "ingeniería institucional" del control público a nivel nacional y que el PP en Medellín está claramente sujeto a los controles propios de la AP, es en la implementación de estos donde se identifican dificultades, en especial en lo relativo al control social.

Las fallas en la implementación de este control encontradas se relacionan con los siguientes tres aspectos: la transparencia de la información acerca del proceso del PP y de sus controles, la rendición de cuentas y la baja participación ciudadana, lo que incide en que específicamente el control social al mismo resulte bajo. En ese orden de ideas, si bien el conocimiento de la ciudadanía respecto al PP ha crecido en los últimos cinco años, este conocimiento es general e incipiente, lo cual obstaculiza un adecuado control al mismo. Lo anterior se refuerza con la escasa presencia del tema del PPy de sus controles en la agenda noticiosa de la ciudad, así como la falta de sistematicidad en la información que provee la Administración, aun cuando se trata de un tema relevante en la agenda pública, sobre todo si se tiene en cuenta la magnitud de los recursos invertidos en el PP. A ello se suma que la información no está disponible en los portales y páginas web de la Administración, sino que los Observatorios y la ciudadanía en general deben solicitarla vía derechos de petición. Con respecto a la rendición de cuentas, se constata que existe de manera general un accountability vertical, que no se focaliza específicamente a las inversiones hechas con el PP, es decir, no se evidencian espacios propiciados por la Administración donde se informe de manera constante y sistemática acerca de la ejecución del PP. Por último, no obstante, se observan esfuerzos sostenidos por parte de la Administración en búsqueda de resignificar la participación ciudadana en los procesos del PP; la misma aún es baja, según reflejan las cifras oficiales. Esto se asocia a prácticas clientelares que persisten

\section{Participación Ciudadana 2012-2017}

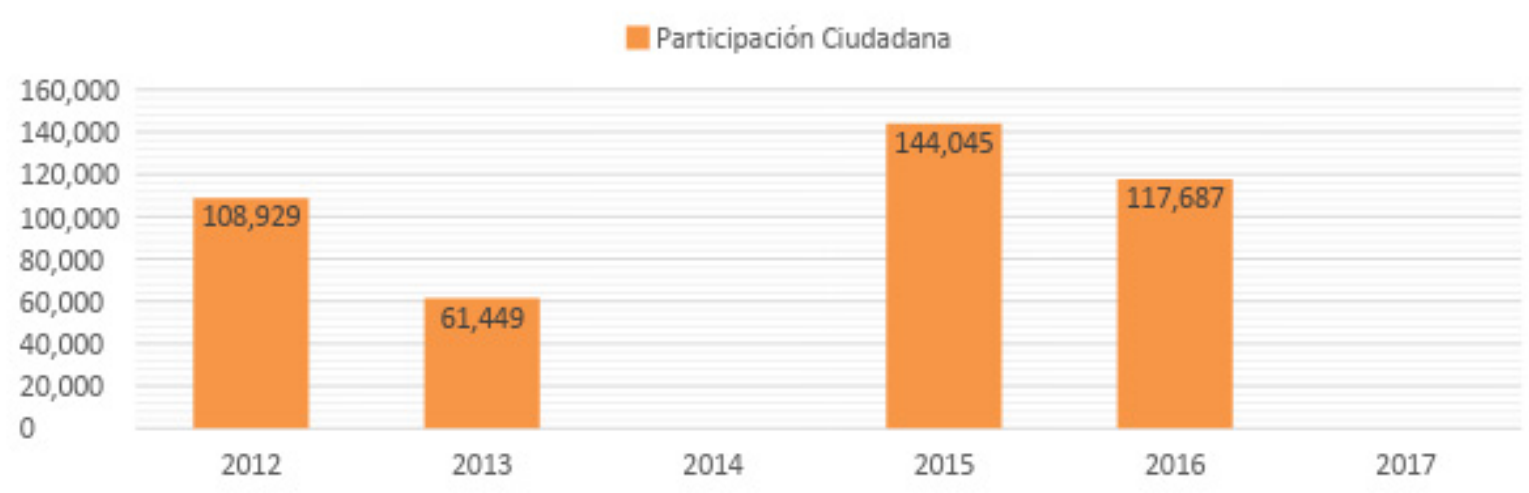

Figura 3. Participación ciudadana en asambleas barriales 2012-2017

Fuente: elaboración propia con datos de la Secretaria de Participación ${ }^{1}$.

$1 \quad$ Se destaca que en 2014 no se cuenta con datos debido a que estaba en curso una demanda al Acuerdo 43 de 2007 y por tanto no se hicieron Asambleas, mientras que, en 2017, al momento de escribir este texto, aún no se habían realizado las Asambleas. 
en las comunidades y a un proceso de elitización de la participación, al cual aluden la mayoría de los entrevistados en sus consideraciones, como un elemento explicativo del escaso interés ciudadano en participar en los procesos del PP y sus controles.

Con base en estos elementos conclusivos, se plantean a continuación algunas recomendaciones: Se requiere que la información del PP sea más visible para la ciudadanía en general, más transparente, de acceso fácil y directo. Adicionalmente, que dicha transparencia no sea solo financiera y fiscal, en términos presupuestales, sino que también sea política, en el sentido de que los resultados del PP se reflejen directamente en los procesos de rendición de cuentas anuales. En particular, se demanda organizar un Sistema de Información del PP que sea pertinente, ágil, completo, oportuno y actualizado. Asimismo, es necesario presentar la información (rubros, bancos de proyectos y ejecuciones) de manera más clara y accesible al público en general. Por ello, se vuelve imprescindible diseñar indicadores que ayuden a ejercer el control ciudadano al PP y promover dicho ejercicio mediante la participación activa en las veedurías ciudadanas, en compañía de la Personería de Medellín y de la Secretaría de Participación. Igualmente, se debe profundizar en la capacitación a los actores involucrados en dicho control y a la ciudadanía en general, en aras de una mayor vigilancia y fiscalización de la gestión de los recursos públicos. Lo anterior incidirá en el aumento de la participación ciudadana en lo referente al control social, toda vez que, a mayor conocimiento del PP, es esperable un mayor control al mismo por parte de la ciudadanía. Si el control social se vuelve más eficaz, esto redundará en el mejoramiento de la política pública del PP en Medellín, consolidándose así un círculo virtuoso en materia de participación ciudadana.

\section{Referencias}

Balbín, C. (2015) Manual de derecho administrativo. Buenos Aires. La Ley.

Betancourt, C. (2005). Presupuesto participativo en Colombia. Caracterización, evolución y perspectivas: revisión conceptual. Bogotá: ESAP, Facultad de investigaciones.

CLAD, (2016). Carta Iberoamérica de Gobierno Abierto. XVII Conferencia Iberoamericana de Ministras y Ministros de Administración Pública y Reforma del Estado, Bogotá, Colombia.
Colombia, Congreso de la República (1993, enero 27). Ley 42 de 1993: Sobre la organización del sistema de control fiscal financiero y los organismos que lo ejercen. Bogotá: Diario Oficial №. 40732.

Colombia, Congreso de la República (1994, mayo 31. Ley 134 de 1994: Por la cual se dictan normas sobre mecanismos de participación ciudadana. Bogotá: Diario Oficial №. 41.373.

Colombia, Congreso de la República (1994, junio 2). Ley 136 de 1994: Por la cual se dictan normas tendientes a modernizar la organización y el funcionamiento de los municipios. Bogotá: Diario Oficial №. 41377.

Colombia, Congreso de la República (1996, diciembre 11). Ley 330 de 1996: Por la cual se desarrolla parcialmente el artículo 308 de la Constitución Politica y se dictan otras disposiciones relativas a las Contralorías Departamentales. Bogotá: Diario Oficial №. 42938

Colombia, Congreso de la República (2000, octubre 9). Ley 617 de 2000: Por la cual se reforma parcialmente la Ley 136 de 1994, el Decreto Extraordinario 1222 de 1986, se adiciona la Ley Orgánica de Presupuesto, el Decreto 1421 de 1993, se dictan otras normas tendientes a fortalecer la descentralización, y se dictan normas para la racionalización del gasto público nacional. Bogotá: Diario Oficial №. 44188

Colombia, Congreso de la República (2003, noviembre 18). Ley 850 de 2003: por medio de la cual se reglamentan las veedurias ciudadanas. Bogotá: Diario Oficial №. 45376

Colombia, Congreso de la República (2007, junio 27). Acto legislativo 01 de 2007: por medio del cual se modifican los numerales 8 y 9 del artículo 135, se modifican los artículos 299 y 312, y se adicionan dos numerales a los artículos 300 y 313 de la Constitución Política de Colombia. Bogotá: Diario Oficial №. 46672.

Colombia, Congreso de la República (2011, julio 12). Ley 1474 de 2011: Por la cual se dictan normas orientadas a fortalecer los mecanismos de prevención, investigación y sanción de actos de corrupción y la efectividad del control de la gestión pública. Bogotá: Diario Oficial №. 48128

Colombia, Congreso de la República (2014, marzo 6). Ley 1712 de 2014: Por medio de la cual se crea la Ley de Transparencia y del Derecho de Acceso a la Información Pública Nacional y se dictan otras disposiciones. Bogotá: Diario Oficial №. 49084

Colombia, Congreso de la República (2015, julio 6). Ley 1757 de 2015: Por la cual se dictan disposiciones en materia de promoción y protección del derecho a la participación democrática. Bogotá: Diario 
Oficial №. 49565

Colombia, Congreso de la República (2015, junio 30). Ley 1755 de 2015: Por medio de la cual se regula el Derecho Fundamental de Petición y se sustituye un título del Código de Procedimiento Administrativo y de lo ContenciosoAdministrativo. Bogotá: Diario Oficial №. 49559

Colombia, Medellin, Concejo Municipal (2007, noviembre 8). Acuerdo Municipal 43 de 2007: Por el cual se crea e institucionaliza la planeación local y el Presupuesto Participativo en el marco del Sistema Municipal de Planeación - Acuerdo 043 de 1996 y se modifican algunos de sus artículos.

Colombia, Medellín, Concejo Municipal (2017, diciembre 21). Acuerdo Municipal 28 de 2017: Por medio del cual se modifica el acuerdo 43 de 2007 y se actualiza el sistema municipal de planeación del municipio de Medellín.

Concejo de Medellín. (mayo 8 de 2017) Artículo 63. Por Medio Del Cual Se Modifica El Acuerdo 43 De 2007 Y Se Actualiza El Sistema Municipal De Planeación Del Municipio De Medellín. [Acuerdo Municipal 28 de 2017].

Constitución política de Colombia [Const.] (1991) Artículos: 40, 91, 135, 209, 270, 299, 300, 308, 312, 313. 2da Ed. Legis

Corbetta, P. (2003). Metodología y técnicas de investigación social. Madrid, España: McGraw-Hill.

DNP (2018) Medición y análisis del desempeño integral de los municipios. Recuperado de https:// www.dnp.gov.co/programas / desarrolloterritorial/evaluacion-y-seguimiento-de-ladescentralizacion/Paginas/documentos-deevaluacion.aspx

Franco, M. H. (2010). La Gestión Pública Local en el ámbito metropolitano. Medellín, Colombia: Área Metropolitana.

Gómez, E. (2007). El presupuesto participativo entre democracia, pobreza y desarrollo. Investigación y desarrollo, 15(1), 56-77.

Harmon, M. y Mayer, R. (1999) Teoria de la organización para la administración pública. México: Fondo de Cultura Económica.

Isaza, C. (2015). El diseño institucional para la rendición de cuentas. Una valoración del caso colombiano. Gestión y Política Pública, 24(2), 339-375.

Marín, F. (2008). Público y Privado. Medellín, Colombia: TEMIS.

Medellín Cómo Vamos. (2009-2017). Encuestas de Percepción [en línea]. Recuperado de https:// www.medellincomovamos.org/quienes-somos/.
Montecinos, E. (2012). Diseños institucionales y participación ciudadana en presupuestos participativos: los casos de Chile, Argentina, Perú, República Dominicana y Uruguay. XVII Congreso Internacional del CLAD sobre la Reforma del Estado y de la Administración Pública. Cartagena de Indias.

Moreno, S. (2014). Control público y gubernamental. Buenos Aires, Argentina: Osmar D. Buyatti-Librería editorial.

Oszlak, O. (2014). Gobierno abierto: Hacia un nuevo paradigma de gestión pública, en: Oscar Oszlak y Kaufman Ester (libro electrónico) Teoría y práctica del gobierno abierto: lecciones de la experiencia internacional, IDRC, RedGEalc y OEA, Agosto 2014.

Pollit, C. y Bouckaert, G. (2004). Public Management reform. A comparative analysis. Oxford: Oxford University Press. 2nd. edition.

Ramírez, M. y Franco, M. (2017) Los controles al presupuesto participativo en Medellin (proyecto de investigación). Universidad EAFIT, Medellín.

Restrepo, J. C. (2015). Hacienda Pública. Bogotá, Colombia: Universidad Externado de Colombia.

Rodríguez, L. (2015) Estructura del poder público en Colombia. Bogotá: Temis.

Restrepo, M. (2011). La administración pública en la Constitución de 1991: sincretismo involuntario entre la burocracia, el gerencialismo y la gobernanza. Estudios Socio-Jurídicos, 13 (1), 365-388.

Sancari, S. (2016). La participación política en la Argentina contemporánea. Buenos Aires. Editorial Departamento de Publicaciones de la Facultad de Derecho UBA/La Ley.

Santofimio, J. O. (1998). Tratado de Derecho Administrativo: Acto administrativo, procedimiento, eficacia y validez (151). Bogotá, Colombia: Universidad Externado de Colombia.

Urán, O. A. (2007). La participación ciudadana en la planeación y financiamiento de la ciudad como institución democrática emergente. Los casos de Manchester, Medellín y Porto Alegre. Revista Controversia, (N: 189) 173-211.

Valadés, D. (2005). El control del poder. Buenos Aires, Argentina: EDIAR. 